\title{
Neural Systems Underlying Opiate Addiction
}

\author{
Taco J. De Vries ${ }^{1}$ and Toni S. Shippenberg ${ }^{2}$ \\ ${ }^{1}$ Research Institute Neurosciences Vrije Universiteit, Drug Abuse Program, Department of Medical Pharmacology, Vrije \\ Universiteit Medical Center, 1081 BT Amsterdam, The Netherlands, and IIntegrative Neuroscience Section, Behavioral \\ Neuroscience Branch, National Institutes of Health/National Institute on Drug Abuse Intramural Research Program, \\ Baltimore, Maryland 21224
}

Opiate addiction is a chronically relapsing disorder that is characterized by compulsive drug taking, an inability to limit intake, and bouts of intense drug craving that can be precipitated by the mere presence of people, places, or objects previously associated with drug use. Although knowledge of the neural mechanisms that underlie the transition from casual drug use to addiction is still incomplete, the development of animal models that enable differentiation of the various stages of the addiction process have provided new insights regarding the neural substrates on which opiates act to affect and subsequently control behavior. Data derived from these models are consistent with the hypothesis that opiates, like psychostimulants, are initially abused by virtue of their rewarding or hedonic effects. However, as will be discussed in this review, the repeated use of opiates induces alterations in neurotransmitter and neuropeptide systems that regulate incentive-motivation and stress-responsiveness. Increasing evidence indicates that the dysregulation of these systems underlies the compulsive use and loss of control of drug-taking that characterizes opiate and other addictions.

Studies examining the neural basis of drug addiction have been guided by the premise that the motivation of an addict to take drugs results from the desire to experience the hedonic (e.g., rewarding) effects of the drug as well as from the desire to avoid the anhedonia and aversive consequences of drug withdrawal (Wikler, 1948; Koob et al., 1989). More recently, it has been posited that repeated drug use induces long-lasting adaptations in neural systems that mediate a subcomponent of drug reward, termed incentive salience (Robinson and Berridge, 1993). Hypersensitivity (e.g., sensitization) of these systems is hypothesized to lead to an enhanced incentive value of drug-related stimuli, compulsive patterns of drug seeking, and the vulnerability to relapse that persists long after the cessation of drug use.

In view of the documented involvement of the mesoaccumbens dopamine (DA) system in incentive motivation and psychostimulant-induced reward (Koob et al., 1998; Schultz et al., 1998), studies examining the neural basis of opiate addiction have focused on the mesolimbic DA projection from the ventral tegmental area (VTA) to the nucleus accumbens (NAc), and to a lesser extent on its afferent and efferent projection areas such as medial prefrontal cortex (mPFC), amygdala, and ventral pallidum. In contrast to the study of psychostimulants, a systematic examination of the neuroanatomical and neurochemical substrates un-

Correspondence should be addressed to T. J. De Vries, Research Institute Neurosciences Vrije Universiteit, Drug Abuse Program, Department of Medical Pharmacology, Vrije Universiteit Medical Center, Van der Boechorststraat 7, 1081 BT Amsterdam, The Netherlands. E-mail: tj.de_vries.pharm@med.vu.nl.

Copyright (C) 2002 Society for Neuroscience 0270-6474/02/223321-05\$15.00/0 derlying the various stages of opiate addiction is only just beginning.

\section{Systems involved in opiate self-administration}

Opiate drugs exert their effects by binding to three opioid receptor types $(\mu, \delta$, and $\kappa)$ and mimicking the actions of endogenous opioid peptides, the endorphins, endomorphins, enkephalins, and dynorphins. The $\mu$-opioid receptor (MOR) subtype is critical for the rewarding effects of heroin and morphine. Blockade of MORs but not other opioid receptors attenuates opiate selfadministration, and constitutive deletion of MORs attenuates the conditioned preferences that animals exhibit for contextual cues previously associated with opiate administration (Negus et al., 1993; Matthes et al., 1996). Opiates induce membrane hyperpolarization and neuronal inhibition in multiple structures, including those that provide major afferent input to the VTA; i.e., NAc and ventral pallidum as primary sources of GABA input, PFC, amygdala, and mediodorsal thalamus as primary sources of glutamate input, and the pedunculopontine tegmental nucleus as a source of acetylcholine input. These structures, which comprise the cortical-pallidal-striatal circuit, are characterized by a high density of opiate receptors (Mansour et al., 1995) and dense reciprocal connections (Groenewegen et al., 1996). This circuit has been implicated in the mediation of goal-directed behavior (Mogenson et al., 1980) and the rewarding effects of psychostimulants (Pierce and Kalivas, 1997; Koob et al., 1998).

Blockade of MORs in the VTA or NAc attenuates heroin self-administration as well as the conditioned approach behavior that develops to cues associated with morphine administration, whereas infusion of opiates into these regions support these behaviors (for review, see Shippenberg and Elmer, 1998). The integrity of the NAc is essential for opiate and psychostimulant self-administration (Zito et al., 1985). These findings are consistent with the hypothesis that a similar circuitry mediates the rewarding effects of these agents.

MOR agonists activate VTA DA neurons and enhance DA release in the NAc via inhibition of GABA neurons (DiChiara and Imperato, 1988; Johnson and North, 1992). Whether DA is the specific effector responsible for the rewarding effects of opiates, as has been demonstrated for psychostimulants, remains controversial. In particular, it is unclear whether these effects are specific to the encoding of the rewarding effects of opiates or represent a more generalized role of DA in reward prediction function (Schultz et al., 1998). Heroin self-administration in rats is associated with both tonic and phasic increases in NAc DA release and is attenuated by the intra-VTA infusion of a GABA-B receptor antagonist (Kiyatkin et al., 1993; Xi and Stein, 1999). The pattern of VTA cell firing within a single self- 
administration session is consistent with the view that mesocorticolimbic DA activation is important for the activational and motivational aspects of heroin-taking behavior in experienced individuals. It is also in accord with an important role of DA release and NAc DA D1 receptors in the conditioned responses that develop to environmental cues predicting opiate administration (Shippenberg and Elmer, 1998). Electrophysiological studies, however, indicate that although overlapping subpopulations of NAc and mPFC neurons may become active during opiate and psychostimulant self-administration, heterogeneous neuronal circuits mediate the rewarding actions of these drugs (Chang et al., 1998). Behavioral evidence supports this conclusion. Thus, although NAc NMDA receptors are required for stimulant selfadministration, this is not the case for heroin (for review, see Trujillo, 2000). Similarly, the pedunculopontine nucleus, which receives extensive projections from regions comprising the cortical-striatal-thalamic circuit, is necessary for the conditioned reinforcing effects of opiates but not psychostimulants (Bechara et al., 1998). Interestingly, however, and in contrast to psychostimulants, there is increasing evidence for involvement of cannabinoid systems in mediating the rewarding effects of opiates. CB1 receptor antagonists or deletion of the $\mathrm{CB} 1$ receptor prevents acquisition of morphine self-administration and the conditioned reinforcing effects of this opiate (Ledent et al., 1999; Mas-Nieto et al., 2001). Modulation of the biochemical and pharmacological effects of cannabinoids by opioid receptor ligands, together with the anatomical distribution of $\mathrm{CB} 1$ receptors in the cortical-pallidalthalamic circuitry, suggests that there may be considerable overlap in the neural substrates mediating the rewarding effects of cannabinoids and opiates (Manzanares et al., 1999).

\section{Neuroadaptations resulting from chronic opiate use}

As with psychostimulants, cessation of chronic opiate use induces functional changes in mesolimbic DA neurons opposite to those observed during drug administration (Diana et al., 1993). Decreased DA neurotransmission may underlie anhedonia and dysphoria during the early phase of drug abstinence, and avoidance of these aversive states may lead to reinstatement of drug use (Koob et al., 1989). Fundamental questions exist as to whether the aversive effects of opiate withdrawal are the primary impetus leading to relapse. However, it is clear that DA D2 receptor agonists attenuate somatic signs of opiate withdrawal (Harris and Aston-Jones, 1994). In contrast, DA D2 receptor antagonists induce affective signs of withdrawal in morphine-dependent animals and attenuate the conditioned reinforcing effects of opiates in dependent animals (Funada and Shippenberg, 1996; Bechara et al., 1998). Therefore, DA mechanisms are involved in the aversive effects of opiate withdrawal, suggesting that the motivational effects of opiate withdrawal result, at least in part, from the disruption of the same circuits implicated in mediating drug reward.

Not surprisingly, repeated opiate use alters the activity of NAc medium spiny neurons that are primary targets of DA neurons. These output neurons, which contain GABA and the opioid peptides dynorphin and enkephalin, as well as substance P, project to the ventral pallidum and VTA. They also have extensive axon collaterals in the NAc. Alterations in these output neurons may contribute to the aversive consequences of opiate withdrawal.

The administration of opioid receptor antagonists, such as naloxone, to morphine-dependent animals produces somatic and affective signs of withdrawal. These effects have been attributed to the antagonism of MORs in the NAc and other regions, including amygdala, VTA, and locus coeruleus (Stinus et al., 1990). However, expression of enkephalin, an opioid peptide that stimulates NAc DA release, is decreased in the NAc during opiate withdrawal (Turchan et al., 1997). Acute administration of selective $\delta$-opioid receptor (DOR) antagonists to opiatedependent animals precipitates affective signs of withdrawal. However, in contrast to MOR antagonists, they are ineffective in precipitating a quantifiable somatic withdrawal syndrome $(\mathrm{Fu}-$ nada et al., 1996). These findings are noteworthy in view of the postulated involvement of DORs in emotional reactivity (Filliol et al., 2000) and indicate that MOR activation, as has been observed in the ventral pallidum (Olive and Maidment, 1998), may stimulate enkephalin release and that dysregulation of DOR systems may contribute to withdrawal-induced dysphoria. Consistent with this hypothesis is the recent finding of increased cellsurface expression of DORs after chronic morphine exposure (Cahill et al., 2001).

Dynorphin, the endogenous ligand for the $\kappa$-opioid receptor (KOR), is also released by medium spiny neurons. KOR agonists produce dysphoria and negative effective states (Pfeiffer et al., 1986) caused by the activation of NAc opioid receptors and inhibition of DA release (Shippenberg and Elmer, 1998). A tonically active NAc KOR system regulating basal DA release has also been demonstrated. Although acute opiate administration does not modify dynorphin expression, increased peptide expression is observed after abstinence from repeated opiate administration (Bronstein et al., 1988). This effect may result from opiateinduced upregulation of the CAMP pathway and the induction of the gene transcription regulator, cAMP response elementbinding protein (CREB) (Nestler, 2001). The opiate withdrawal syndrome is attenuated after disruption of the genes encoding CREB or KORs (Maldonado et al., 1996; Simonin et al., 1998), suggesting that upregulation of the dynorphin system may be a key homeostatic adaptation that, in the presence of drug, diminishes further drug responsiveness (e.g., enhanced DA release), but that in the absence of drug may contribute to the dysphoria and anhedonia that characterizes the early phase of opiate withdrawal. Evidence that elevated levels of dynorphin may also contribute to alterations in behavior and DA neurotransmission that occur during abstinence from psychostimulants has also been obtained (Shippenberg et al., 2001). Interestingly, protracted abstinence from opiates and psychostimulants is characterized by normalization of dynorphin levels and an enhancement of drugevoked NAc DA release. Hypersensitivity of DA neurons may underlie the long-term expression of behavioral sensitization to various drugs of abuse as well as the reinstatement of compulsive drug-seeking behavior (Robinson and Berridge, 1993; Vanderschuren and Kalivas, 2000), suggesting that alterations in the dynorphin/KOR receptor system may play a global role in drug craving and relapse to addiction.

Repeated use of opiates also induces neuroadaptations in other brain regions (e.g., basolateral amygdala, locus coeruleus, bed nucleus of the stria terminalis) and neurotransmitter systems (e.g., glutamate, norepinephrine, CRF). Each of these adaptations may be involved in expression of the aversive effects of the opiate-withdrawal syndrome (Kreek and Koob, 1998). Alterations in the activity of CRF neurons are noteworthy given the involvement of stress in compulsive drug seeking and the role of this peptide in regulating DA release and opioid peptides in the mesolimbic system and its projection areas (Kreek and Koob, 1998; Sarnyai et al., 2001). Behavioral and neurochemical results 
indicate that CRF neurons are activated during acute withdrawal from opiates and that this effect may contribute to both the anxiety of withdrawal and the vulnerability to relapse that persists as abstinence progresses.

\section{Relapse to opiates}

Our understanding of the neural systems important for relapse to opiate-seeking behavior is still at its infancy. Recent advances in animal models have indicated that conditions that intensify drug craving or provoke drug relapse in humans (i.e., stress; renewed contact with the drug, or environmental stimuli that have signaled drug availability) reliably reinstate drug seeking in laboratory animals even after prolonged abstinence (Self and Nestler, 1998; Shaham et al., 2000; Stewart, 2000). The strong face validity of these reinstatement models provides a useful tool for studying the neurobiological mechanisms involved in relapse to opiate seeking.

Davis and Smith (1976) first showed that morphine, as well as a stimulus previously associated with the intravenous infusion of morphine, was able to reinstate opiate-seeking behavior in experimental animals. Later studies showed that a priming injection of heroin or exposure to mild unpredictable footshock stress were effective in eliciting heroin-seeking behavior in animals with a previous history of heroin self-administration (Shaham et al., 2000; Stewart, 2000).

Although the role of DA in mediating the rewarding effects of opiates remains controversial, there is substantial evidence for a role of the mesolimbic DA system in mediating the priming effects of opiates on heroin seeking. Intra-NAc infusion of amphetamine, a psychostimulant that stimulates DA release, is effective in reinstating heroin seeking, and a similar response is observed after VTA infusion of morphine doses that increase NAc and mPFC DA release. In contrast, infusions of morphine into the NAc fail to stimulate DA release and are ineffective in opiate reinstatement models (for review, see Stewart, 2000).

DA D2 receptor antagonists block heroin-induced reinstatement (Ettenberg et al., 1996; Shaham and Stewart, 1996), suggesting an important role of this DA receptor. In contrast, the DA D1 receptor antagonist, SCH-23390, attenuates heroin-induced reinstatement only at doses producing motor impairment (Shaham and Stewart, 1996). Data regarding the ability of DA receptor agonists to mimic the effects of heroin priming also indicate involvement of DA D2 receptors in heroin seeking (Wise et al., 1990; De Vries et al., 2002). The priming effect of the DA D2 receptor agonist quinpirole is robust during the first week of withdrawal but dissipates after 3 weeks of withdrawal (De Vries et al., 2002). As discussed above, DA D2 receptor antagonists produce effective signs of withdrawal in morphine-dependent rats (Funada et al., 1996). However, DA D2 receptor agonists administered during the early phase of opiate withdrawal induce marked behavioral activation (Druhan et al., 2000), indicating that DA D2 receptor activation during the early phase of withdrawal may lead, in fact, to enhanced motivation for drug. This conclusion is consistent with a critical role of DA D2 receptors in the motivational effects of opiates in the opiate-dependent as compared with the non-dependent state (Bechara et al., 1998; Dockstader et al., 2001). It may also explain previous inconsistent effects of DA D2 receptor antagonists on heroin selfadministration (Ettenberg et al., 1982; Mello and Negus, 1996).

Priming with the DA D1 receptor agonist SKF 82958 or the non-selective DA receptor agonist apomorphine does not reinstate heroin seeking (De Vries et al., 1999; Stewart, 2000). Therefore, at late withdrawal stages ( $>3$ weeks), neither D1, D2, nor non-selective agonists mimic the priming effects of heroin. Because indirect DA agonists like amphetamine and cocaine are effective in reinstating heroin seeking at later stages of withdrawal (De Vries et al., 1999), the role of DA in mediating heroin seeking that occurs during protracted withdrawal remains unclear.

Data regarding the role of other neurotransmitter systems in opiate relapse is limited. An involvement of glutamatergic neurons in relapse to cocaine seeking has been presented (Cornish and Kalivas, 2000). However, acamprosate, a compound that alters glutamate neurotransmission and is used in alcohol relapse prevention programs, exerts no effect on heroin-induced reinstatement of heroin seeking (Spanagel et al., 1998).

A role of stress in relapse to compulsive drug seeking, as observed in human addicts, has been demonstrated in laboratory animals. Mild footshock stress reliably reinstates heroin seeking in rats (Shaham and Stewart, 1995; Ahmed et al., 2000), an effect that is mimicked by other stressors, including food deprivation. Evidence for involvement of CRF in the response to stress comes from studies showing that CRF antagonists attenuate footshockinduced reinstatement of heroin seeking, an effect that may be meditated within the bed nucleus of the stria terminalis. Also, $\alpha_{2}$-adenoceptor agonists, presumably acting on noradrenergic neurons originating from the lateral tegmental nuclei but not the locus coeruleus, prevent this behavior. Other studies have shown that the effects of stress on relapse are not dependent on the release of corticosterone, are resistant to opioid receptor antagonists, and are relatively insensitive to DA receptor antagonists (for review, see Shaham et al., 2000). Thus, although the effects of heroin priming appear to be mediated by the same DA and opioid pathways involved in reward and dependence, the stress-induced relapse to opiate addiction may result from the activation of a distinct set of neuronal systems. At present, however, fundamental questions exist as to whether there is convergence of these systems and, if so, at what level.

Relatively few studies have examined the neural substrates underlying relapse to opiate seeking in response to stimuli previously associated with opiate administration. Using an operant runway task reinforced by heroin administration, McFarland and Ettenberg (1997) showed that heroin-predictive environmental stimuli reinstate running after this behavior is extinguished. The DA D2 receptor antagonist haloperidol did not modify the incentive motivational effects of these stimuli, suggesting that DA systems may not play a critical role in this behavior. In contrast, DA receptor (particularly D1) antagonists attenuate cue-induced reinstatement of cocaine-seeking behavior (for review, see Shalev et al., 2002). Marked differences between cue-controlled heroin and cocaine seeking have also been observed in second order schedules of reinforcement in which drug seeking is maintained by contingent presentation of drug-paired stimuli. Thus, under similar experimental conditions, discrete drug-associated cues have a weak impact on heroin seeking relative to cocaine seeking (Alderson et al., 2000). Also, basolateral amygdala lesions and partial DA D3 receptor agonists, both of which impair cuecontrolled cocaine seeking (Everitt and Robbins, 2000), fail to alter heroin seeking.

It is unclear to what extent opiate withdrawal functions as a motivational state that enhances the incentive value of opiates and can explain relapse to addiction occurring during protracted abstinence. Attempts to induce relapse to heroin seeking by precipitating withdrawal have been unsuccessful (Shaham and Stewart, 1995; Shaham et al., 1996) (but see Hutcheson et al., 
2001). In those studies in which the drug intake of heroin was sufficient to induce somatic signs of withdrawal symptoms during early withdrawal (1-2 d) (Shaham et al., 1996), extinction behavior, a measure of drug seeking, and footshock-induced reinstatement were maximal at time points in which somatic signs of withdrawal had dissipated (Shalev et al., 2000). These findings and those regarding the relationship between the duration of cocaine abstinence and cue-induced reinstatement of cocaine seeking (Grimm et al., 2001) suggest strongly that the vulnerability to relapse is not related to the severity of the withdrawal signs.

According to the incentive-sensitization theory of addiction (Robinson and Berridge, 1993), neuroadaptations that lead to the drug-induced sensitization underlie the persistence of drugseeking behavior and the vulnerability to relapse that can occur after protracted abstinence. Several studies have shown that the locomotor-activating and conditioned-reinforcing effects of opiates are enhanced after repeated, intermittent administration of opiates (Shippenberg et al., 1996; Vanderschuren and Kalivas, 2000). Recently, opiate sensitization was demonstrated after protracted abstinence from heroin self-administration (De Vries et al., 1998). Interestingly, priming-induced reinstatement of heroin seeking was found only with opioid and DA ligands that were able to elicit a sensitized locomotor response in opiate-pretreated animals (De Vries et al., 1999; Vanderschuren et al., 1999). These findings are in accord with the postulated role of the mesolimbic DA system in mediating both the incentive-motivational and sensitizing properties of opiates and other drugs of abuse (Robinson and Berridge 1993; Vanderschuren and Kalivas, 2000).

Repeated exposure to drugs of abuse may also sensitize neuronal systems involved in stress-responsiveness (Kreek and Koob, 1998; Sarnyai et al., 2001). Recent studies indicate that the duration of withdrawal after heroin self-administration is a critical factor in mediating footshock stress-induced reinstatement of heroin seeking (Shalev et al., 2000). Thus, stress-induced reinstatement was absent on day 1 of withdrawal and was greatest after 1-2 weeks of abstinence. Ahmed et al. (2000) reported that rats that had longer access (11 hr/day) to heroin exhibit an enhanced sensitivity to the reinstating properties of footshock than rats that had shorter access (1 hr/day).

These reinstatement results agree with neuroadaptation theories positing that drugs of abuse induce progressive and longlasting neuronal changes that depend, at least in part, on the amount of drug exposure (Pierce and Kalivas 1997). The apparent dissociation between withdrawal severity and vulnerability to opiate relapse further suggests that drug-enhancing, proponent processes are more likely to play a role in the persistence of drug craving and relapse than drug-opposing, opponent processes, which underlie tolerance and withdrawal.

\section{Concluding remarks and future perspectives}

As is apparent from the mini-reviews in this issue of the journal, most studies have focused on psychostimulants, leaving many issues related to opiate addiction and, in particular, to opiate relapse unanswered. Although application of a systems approach to the study of opiate addiction is only just beginning, recent findings challenge previous notions regarding the role of one particular neurotransmitter or brain region in the initiation and maintenance of the addiction process. Rather they indicate that the repeated use of opiates affects the activity of several neurotransmitter and neuropeptide systems in brain circuits that regulate mood and affect and that these neuroadaptations underlie behavioral alterations that define opiate addiction. It is also apparent that precipitation of relapse by renewed drug exposure, drug-associated stimuli, and stress is mediated not only by distinct neuronal pathways, but that the relative contribution or sensitivity of these pathways to such effects varies as a function of the duration of withdrawal. When viewed from the perspective of medications development, these results suggest that the stage of the addiction cycle must be considered when evaluating the efficacy of a particular treatment in preventing relapse to opiate addiction. They further suggest that drugs effective in reducing compulsive opiate seeking during one stage of the addiction cycle may be ineffective in another and that a multi-targeted approach to the treatment of opiate addiction is essential.

\section{REFERENCES}

Ahmed SH, Walker JR, Koob GF (2000) Persistent increase in the motivation to take heroin in rats with a history of drug escalation. Neuropsychopharmacology 22:413-421.

Alderson HL, Robbins TW, Everitt BJ (2000) Heroin self-administration under a second-order schedule of reinforcement: acquisition and maintenance of heroin-seeking behaviour in rats. Psychopharmacology 153: 120-133.

Bechara A, K Nader K, Van der Kooy D (1998) A two-separatemotivational-systems hypothesis of opioid addiction. Pharmacol Biochem Behav 59:1-17.

Bronstein D, Trujillio K, Akil H, (1988) Effects of morphine treatment on endogenous opioid biosynthesis. NIDA Res Monogr 90:256-265.

Cahill CM, Morinville A, Lee M-C, Vincent J-P, Collier B, Beaudet A (2001) Prolonged morphine treatment targets $\delta$ opioid receptors to neuronal plasma membranes and enhances $\delta$-mediated antinociception. J Neurosci 21:7598-7607.

Chang JY, Janak PH, Woodward DH (1998) Comparison of mesocorticolimbic neuronal responses during cocaine and heroin selfadministration in freely moving rats. J Neurosci 18:3098-3115.

Cornish JL, Kalivas PW (2000) Glutamate transmission in the nucleus accumbens mediates relapse in cocaine addiction. J Neurosci 20:11-15.

Davis WM, Smith SG (1976) Role of conditioned reinforcers in the initiation, maintenance and extinction of drug-seeking behavior. Pavlovian J Biol Sci 11:222-236.

De Vries TJ, Schoffelmeer ANM, Binnekade R, Mulder AH, Vanderschuren LJMJ (1998) Drug-induced reinstatement of heroin- and cocaine-seeking behaviour following long-term extinction is associated with expression of behavioural sensitization. Eur $\mathrm{J}$ Neurosci 10:3565-3571.

De Vries TJ, Schoffelmeer ANM, Binnekade R, Vanderschuren LJMJ (1999) Dopaminergic mechanisms mediating the incentive to seek cocaine and heroin following long-term withdrawal of IV drug selfadministration. Psychopharmacology 143:254-260.

De Vries TJ, Schoffelmeer ANM, Binnekade R, Raas $\varnothing$ H, Vanderschuren LJMJ (2002) Relapse to cocaine- and heroin-seeking behavior mediated by dopamine D2 receptors is time-dependent and associated with behavioral sensitization. Neuropsychopharmacology 26:18-26.

Diana M, Pistis M, Carboni S, Gessa GL, Rossetti ZL (1993) Profound decrement of mesolimbic dopaminergic neuronal activity during ethanol withdrawal syndrome in rats: electrophysiological and biochemical evidence. Proc Natl Acad Sci USA 90:7966-7969.

DiChiara G, Imperato A (1988) Drugs abused by humans preferentially increase synaptic dopamine concentrations in the mesolimbic system of freely moving rats. Proc Natl Acad Sci USA 85:5274-5278.

Dockstader CL, Rubinstein M, Grandy DK, Low MJ, van der Kooy D (2001) The D-2 receptor is critical in mediating opiate motivation only in opiate-dependent and withdrawn mice. Eur J Neurosci 13:995-1001.

Druhan JP, Walters CL, Aston-Jones G (2000) Behavioral activation induced by D-2-like receptor stimulation during opiate withdrawal. J Pharmacol Exp Ther 294:531-538.

Ettenberg A, Pettit HO, Bloom FE, Koob GF (1982) Heroin and cocaine intravenous self-administration in rats: mediation by separate neural systems. Psychopharmacology 78:204-209.

Ettenberg A, MacConell LA, Geist TD (1996) Effects of haloperidol in a response-reinstatement model of heroin relapse. Psychopharmacology 124:205-210.

Everitt BJ, Robbins TW (2000) Second-order schedules of drug reinforcement in rats and monkeys: measurement of reinforcing efficacy and drug-seeking behaviour. Psychopharmacology 153:17-30.

Filliol D, Ghozland S, Chluba J, Martin M, Matthes HW, Simonin F, Befort K, Gaveriaux-Ruff C, Dierich A, LeMeur M, Valverde O, Maldonado R, Kieffer BL (2000) Mice deficient for delta- and muopioid receptors exhibit opposing alterations of emotional responses. Nat Genet 25:195-200.

Funada M, Shippenberg TS (1996) Differential involvement of D1 and 
D2 dopamine receptors in the expression of morphine withdrawal signs in rats. Behav Pharmacol 7:448-453.

Funada M, Schutz CG, Shippenberg TS (1996) Role of delta-opioid receptors in mediating the aversive stimulus effects of morphine withdrawal in the rat. Eur J Pharmacol 300:17-24.

Grimm JW, Hope BT, Wise RA, Shaham Y (2001) Neuroadaptation: incubation of cocaine craving after withdrawal. Nature 412:141-142.

Groenewegen HJ, Wright CI, Beijer VJ (1996) The nucleus accumbens: gateway for limbic structures to reach the motor system? Prog Brain Res 107:485-551.

Harris GC, Aston-Jones G (1994) Involvement of D2 dopamine receptors in the nucleus accumbens in the opiate withdrawal syndrome. Nature 371:155-157.

Hutcheson DM, Everitt BJ, Robbins TW, Dickinson A (2001) The role of withdrawal in heroin addiction: enhances reward or promotes avoidance? Nat Neurosci 4:943-947.

Johnson SW, North RA (1992) Opioids excite dopamine neurons by hyperpolarization of local interneurons. J Neurosci 12:483-488.

Kiyatkin EA, Wise RA, Gratton A (1993) Drug- and behaviorassociated changes in dopamine-related electrochemical signals during intravenous heroin self-administration in rats. Synapse 14:60-72.

Koob GF, Stinus L, Le Moal M, Bloom FE (1989) Opponent process theory of motivation: neurobiological evidence from studies of opiate dependence. Neurosci Biobehav Rev 13:135-140.

Koob GF, Sanna PP, Bollm FE (1998) Neuroscience of addiction. Neuron 21:467-476.

Kreek MJ, Koob GF (1998) Drug dependence: stress and dysregulation of brain reward pathways. Drug Alcohol Depend 51:23-47.

Ledent C, Valverde O, Cossu G, Petitet F, Aubert JF, Beslot F, Bohme GA, Imperato A, Pedrazzini T, Roques BP, Vassart G, Fratta W, Parmentier M (1999) Unresponsiveness to cannabinoids and reduced addictive effects of opiates in CB1 receptor knockout mice. Science 283:401-404

Maldonado R, Blendy J, Tzavara E, Gass P, Roques BP, Hanoune J, Schutz G (1996) Reduction of morphine abstinence in mice with a mutation in the gene encoding CREB. Science 273:657-659.

Mansour M, Fox CA Burke S, Akil H, Watson SJ (1995) Immunohistochemical localization of the cloned mu opioid receptor in the rat CNS. J Chem Neuroanat 8:283-305.

Manzanares A, Corchero J, Romero J, Fernandez-Ruiz JJ, Ramos JA, Fuentes JA (1999) Pharmacological and biochemical interactions between opioids and cannabinoids. Trends Pharmacol Sci 20:287-294.

Mas-Nieto M, Pommier B, Tzavara ET, Caneparo A, Da Nascimento S, Le Fur G, Rogues BP, Noble F (2001) Reduction of opioid dependence by the CB1 antagonist SR141716A in mice: evaluation of the interest in pharmacotherapy of opioid addiction. $\mathrm{Br} \mathrm{J}$ Pharmacol 132:1809-1816.

Matthes HW, Maldonado R, Simonin F, Valverde O, Slowe S, Kitchen I, Befort K, Dierich A, Le Meur M, Dolle P, Tzavara E, Hanoune J, Roques BP, Kieffer BL (1996) Loss of morphine-induced analgesia, reward effect and withdrawal symptoms in mice lacking the mu-opioidreceptor gene. Nature 383:819-823.

McFarland K, Ettenberg A (1997) Reinstatement of drug-seeking behavior produced by heroin-predictive environmental stimuli. Psychopharmacology 131:86-92.

Mello NK, Negus SS (1996) Preclinical evaluation of pharmacotherapies for treatment of cocaine and opioid abuse using drug selfadministration procedures. Neuropsychopharmacology 14:375-424.

Mogenson GJ, Jones DL, Yin CY (1980) From motivation to action: functional interface between the limbic system and the motor system. Prog Neurobiol 14:69-97.

Negus SS, Burke TF, Medzihradsky F, Woods JH (1993) Effects of opioid agonists selective for mu, kappa and delta opioid receptors on schedule-controlled responding in rhesus monkeys: antagonism by quadazocine. J Pharmacol Exp Ther 267:896-903.

Nestler EJ (2001) Molecular basis of long-term plasticity underlying addiction. Nat Rev Neurosci 2:119-128.

Olive MF, Maidment NT (1998) Repeated heroin administration increases extracellular opioid peptide-like immunoreactivity in the globus pallidus/ventral pallidum of freely moving rats. Psychopharmacology 139:251-254.

Pfeiffer A, Brantl V, Herz A, Emrich HM (1986) Psychotomimesis mediated by kappa opiate receptors. Science 233:774-776.

Pierce RC, Kalivas PW (1997) A circuitry model of the expression of behavioral sensitization to amphetamine-like psychostimulants. Brain Res Rev 25:192-216.

Robinson TE, Berridge KC (1993) The neural basis of drug craving: an incentive-sensitization theory of addiction. Brain Res Rev 18:247-291.

Sarnyai Z, Shaham Y, Heinrichs SC (2001) The role of corticotropinreleasing factor in drug addiction. Pharmacol Rev 53:209-243.

Schultz W, Tremblay L, Hollerman J (1998) Reward prediction in primate basal ganglia and frontal cortex. Neuropharmacology 37:421-429.

Self DW, Nestler EJ (1998) Relapse to drug-seeking: neural and molecular mechanisms. Drug Alcohol Depend 51:49-60.

Shaham Y, Stewart J (1995) Stress reinstates heroin-seeking in drug free animals: an effect mimicking heroin, not withdrawal. Psychopharmacology 119:334-341

Shaham Y, Stewart J (1996) Effects of opioid and dopamine receptor antagonists on relapse induced by stress and re-exposure to heroin in rats. Psychopharmacology 125:385-391.

Shaham Y, Rajabi H, Stewart J (1996) Relapse to heroin-seeking in rats under opioid maintenance: the effects of stress, heroin priming, and withdrawal. J Neurosci 16:1957-1963.

Shaham Y, Erb S, Stewart J (2000) Stress-induced relapse to heroin and cocaine seeking in rats: a review. Brain Res Rev 33:13-33.

Shalev U, Morales M, Hope B, Yap J, Shaham Y (2000) Timedependent changes in extinction behavior and stress-induced reinstatement of drug seeking following withdrawal from heroin in rats. Psychopharmacology 156:98-107.

Shalev U, Grimm JW, Shaham Y (2002) Neurobiology of relapse to heroin and cocaine seeking: a review. Pharmacol Rev 54:1-42.

Shippenberg TS, Elmer G (1998) The neurobiology of opiate reinforcement. Crit Rev Neurobiol 14:267-303.

Shippenberg TS, Heidbreder C, LeFevour A (1996) Sensitization to the conditioned rewarding effects of morphine: pharmacology and temporal characteristics. Eur J Pharmacol 299:33-39.

Shippenberg TS, Chefer VI, Zapata A, Heidbreder C (2001) Modulation of the behavioral and neurochemical effects of psychostimulants by kappa-opioid receptor systems. Ann NY Acad Sci 937:50-73.

Simonin F, Valverde O, Smadja C, Slowe S, Kitchen I, Dierich A, Le Meur M, Roques BP, Maldonado R, Kieffer BL (1998) Disruption of the kappa-opioid receptor gene in mice enhances sensitivity to chemical visceral pain, impairs pharmacological actions of the selective kappa-agonist U-50,488H and attenuates morphine withdrawal. EMBO J 17:886-897.

Spanagel R, Sillaber I, Zieglgansberger W, Corrigall WA, Stewart J, Shaham Y (1998) Acamprosate suppresses the expression of morphine induced sensitization in rats but does not affect heroin self administration or relapse induced by heroin or stress. Psychopharmacology 139:391-401.

Stewart J (2000) Pathways to relapse: the neurobiology of drug- and stress-induced relapse to drug-taking. J Psychiatry Neurosci 25:125-136.

Stinus L, Le Moal M, Koob GF (1990) Nucleus accumbens and amygdala are possible substrates for the aversive stimulus effects of opiate withdrawal. Neuroscience 37:767-773.

Trujillo KA (2000) Are NMDA receptors involved in opiate-induced neural and behavioral plasticity? A review of preclinical studies. Psychopharmacology 151:121-141.

Vanderschuren LJMJ, Schoffelmeer ANM, Mulder AH, De Vries TJ (1999) Dopaminergic mechanisms mediating the long-term expression of locomotor sensitization following pre-exposure to morphine or amphetamine. Psychopharmacology 143:244-253.

Vanderschuren LJMJ, Kalivas PW (2000) Alterations in dopaminergic and glutamatergic transmission in the induction and expression of behavioral sensitization: a critical review of preclinical studies. Psychopharmacology 151:99-120.

Wikler A (1948) Recent progress in research on the neurophysiological basis of morphine addiction. Am J Psychiatry 105:329-338.

Wise RA, Murray A, Bozarth MA (1990) Bromocriptine self-administration and bromocriptine-reinstatement of cocaine-trained and herointrained lever pressing in rats. Psychopharmacology 100:355-360.

Xi ZX, Stein EA (1999) Baclofen inhibits heroin self-administration behavior and mesolimbic dopamine release. J Pharmacol Exp Ther 290:1369-1374.

Zito KA, Vickers G, Roberts DC (1985) Disruption of cocaine and heroin self-administration following kainic acid lesions of the nucleus accumbens. Pharmacol Biochem Behav 23:1029-1036. 